\title{
Physical and Mathematical Model of Heart and Cardiovascular System
}

\author{
Aditya Kundu', Ananya Kundu², Goutam Kumar Kundu ${ }^{3}$ \\ ${ }^{1}$ MBBS student, All India Institute of Medical Sciences, Rishikesh, Uttarakhand, India. \\ ${ }^{2}$ MBBS Student, Nil Ratan Sircar Medical College \& Hospital, Kolkata, West Bengal, India. \\ ${ }^{3}$ AGM, NTPC Limited/Farakka, Murshidabad, West Bengal, India.
}

\section{Abstract}

The cardiovascular system is modelled as a fluid flow system consisting of networks of pumps and piping systems. A mathematical model relating different cardiovascular parameters was developed. The change in cardiovascular parameters with individuals' physical activity level, habits and environmental factors was established. The models used to predict how an individual can control the cardiovascular parameters to be healthy and diagnosing problems in the system.

Keywords: Blood Pressure; Circulatory system modelling; Heart Rate.

\section{Introduction}

The cardiovascular system is considered as a set of pumps connected with combination of series and parallel resistances and capacitances or compliances (consisting of blood vessels) [1, 2]. It is analogous to fluid flow system with variable viscous forces and connected with storage tanks (capacitance or compliances). Corresponding to every fluid flow circuit, there exists an equivalent electrical circuit having source of energy like battery or electrical generator, resistances and capacitances. So laws applicable to equivalent electrical circuit are applicable to cardiovascular system. Using those laws, the relationship between parameters of cardiovascular system was established.

Heart is agglomerate of two separate pumps; right heart that pumps blood through the respiratory organ, and left heart that pumps blood through the peripheral organs. Each of these pumps is a pulsatile two-chamber pump composed of an atrium and a ventricle. Each atrium is a weak primer pump for the ventricle, helping to move blood into the ventricle. Ventricles in a following rythm supply the main pumping force that propels the blood either (1) through the pulmonary circulation by the right ventricle or (2) through the peripheral circulation by the left ventricle. The specialized excitatory and conductive fibres, exhibit either automatic rhythmical electrical discharge in the form of action potentials or conduction of the action potentials through the heart, providing an excitatory system that controls the rhythmical beating of the heart [2].

The heart beats, stroke volume, flow delivered and blood pressure of the circulatory system and the effect of different parameters on them were widely studied.

The stroke length and hence stroke volume of heart depends on venous return. The increase in venous return stretches the heart muscle more and exerts more pressure and stroke volume increases [2].

eISSN: 2523-6709

pISSN: $2523-6695$

DOI: $10.31878 /$ ijcrpp.2020.42.02
The effect of non-pharmacological interventions like salt restriction, weight change, physical and mental stress control, alcohol consumption, food habit on blood pressure was examined and correlated [3-9]. Sedentary behaviors and its impact on health were studied by Matthews et al [10]. For all age-groups and in both sexes, a direct and strong relationship between weight and blood pressure was established [11].

Potassium in the extracellular fluids causes the heart to become dilated and flaccid and also decreses the heart rate. Excess of calcium ions promotes spastic contraction. Cardiac muscle has three types of membrane ion channels that play important roles in causing the voltage changes of the action potential. They are (1) fast sodium channels, (2) slow sodium-calcium channels, and (3) potassium channels $[1,2]$.

Increased body temperature increases heart rate and decrease in body temperature decreases it [1]. Heart Rate depends both on non-modifiable factors (age, gender and ethinicity) and modifiable factors (Physiological and Pathological factors, Lifestyle factors, Neuropsychological factors, and Environmental factors [12].

The factors that determine the resistance $(\mathrm{R})$ of a blood vessel to blood flow are expressed by the Poiseuille equation:

$\mathrm{R}=8 * \mathrm{~h}$ (viscosity of blood) *1 (length of blood vessel) / $\{\text { radius of blood vessel }(\mathrm{r})\}^{\wedge} 4[1]$.

Kotchen et al [13] found Blood pressure at one age is predictive of blood pressure at a later age. Bowman etal [14] found that systolic Blood Pressure is a strong, consistent, and independent predictor of Cardio Vascular Disease death for men aged 39 to 84 years old. Rockwood and Howlett [15] found that blood pressure changed little in relation to age in all groups, except in individuals with untreated hypertension. Penuela and Penuela [16] concluded "age shows a positive but divergence relationship with standard deviation for day and night with diastolic and systolic blood pressure. Blood pressure variation both systolic and diastolic at day and night were found higher in female".

Effect of gene on hypertension has been established. It

Correspondence: Shivalkar Surendra, Room No.11, Saidham Building, N. M. Joshi marg, Lower Parel, Mumbai, Maharashtra, India. Email: snehabhatkar6353@gmail.com 
involves multiple genes with only mild effects on phenotype, gene-gene interactions (epistasis), and genes that manifest as multiple traits [17-20].

Integrative model of cardiovascular system with arterial network and flow of blood through different organ was established.

The peripheral circulation is divided into the upper body, renal, splanchnic, and lower extremity sections; the intrathoracic superior, inferior vena cava, and extra-thoracic vena cava are identified separately. The model thus consists of compartments, each of which is represented by resistance $(\mathrm{R})$ and compliance or capacitance $(\mathrm{C})[1,21]$. Compliance or capacitance here is the volume of blood the vessel can hold per unit pressure.

Cardiac output is distributed among various organs: approximately $15 \%$ of the cardiac output is delivered to the brain via the cerebral arteries, $5 \%$ is delivered to the heart via the coronary arteries, $25 \%$ is delivered to the kidneys via the renal arteries. The percentage distribution of cardiac output among the various organ systems is not fixed [1].

Research Gap: The physical model or mathematical model of circulatory system as a whole is unavailable.

Objectives:

I. To Build up a physical model of Cardiovascular system

II. To Build up mathematical models relating cardiovascular parameters

III. Establishing relationship of blood pressure with level of exercise

IV. Applying models for clinical purposes

\section{Materials and Methods}

The research has been carried out in two stages. From review of literature about the blood circulation loops and its analogy with similar electrical (heart as variable voltage source and blood vessels as resistors in parallel with capacitors) and mechanical system (heart as peristoltic pump and blood vessels as resistive frictions in parallel with a storage tank), model for circulatory system was prepared. First secondary data has been collected from published data sources and from available laws and relationships between parameters, the variables used in models were computed. In the second state primary data was collected. The large sample (400) was taken [22] by stratified random sampling. From the collected primary data model has been validated.

\section{Developing Models:}

\section{Physical Models:}

Literature indicates heart can be considered as variable speed, variable output pump of reciprocating type or it can be compared with a controllable variable voltage battery. The circulatory system can be considered as a system consisting of series and parallel resistances (that causes hindrance to blood circulation like friction and drops blood pressure) and connected with compliances/ capacitance (that acts like electrical capacitor or a storage tank connected with system, if pressure of the system increases blood will flow to the storage tank which has low pressure or head so that flow through system not increases due to increase in system pressure similarly if pressure decreases blood comes from storage tank to system, hence it tries to maintain flow or opposes change in flow). When pressure of the circuit increases it will exert more force on the wall of organs of circulatory system and holds more volume so that flow through the system not changes much with changing pressure, opposite is the case in-case pressure decreases. Resistances and Compliances are of adjustable types that is can be changed based on requirement of blood in their respective organs. The discharge of reciprocating pump per second $(\mathrm{Q})=$ Discharge in one revolution * number of revolution per second [23]. The pressure developed by the piston of pump $=$ Constant $*$ frequency^ $2 *$ Cos $\left(2 \pi^{*}\right.$ frequency*time) [23]. Accordingly for Heart the flow of blood $(\mathrm{Q})=$ Ventricular Stroke Volume $(\mathrm{SV}) *$ Heart Rate ( $\mathrm{n}$ in beats/second). $\mathrm{SV}=$ End Diastolic volume - End Systolic volume. The Pulse Pressure of Heart $(\mathrm{PP})=$ Constant $(\mathrm{A}) *$ Square of Heart Rate $\left(\mathrm{n}^{\wedge} 2\right) *$ $\operatorname{Cos}(2 \pi * n * t+\alpha)$ where $t$ is time and $\alpha$ is the phase angle at time zero or the time at which heart muscle starts constructing. The value of $\alpha$ will be $180^{\circ}$ or $\pi$ as diastolic pressure is minimum. The pulse pressure due to stroke of heart exists only in arota, all arteries and arterioles and not exists in capillaries and veins as their compliances absorbs the pulse like capacitor in electricity. Pulse Pressure in different circulatory part is governed by the same equation as in heart only the value of constant is different.

The exchanges of gases in capillaries take place at very low velocity. The movement muscles of the organs should also provide energy to the blood to reach it to heart despite low velocity at capillaries. So it can be considered as variable output pumps. In view of the above and the information of Constanzo [1] and other literature review, Circulatory system can be represented as in figure 1 . Similarly as per the information of Kim et al [21] and other literature review, Circulatory system can be represented as in figure 2 . The symbols used are as follows:

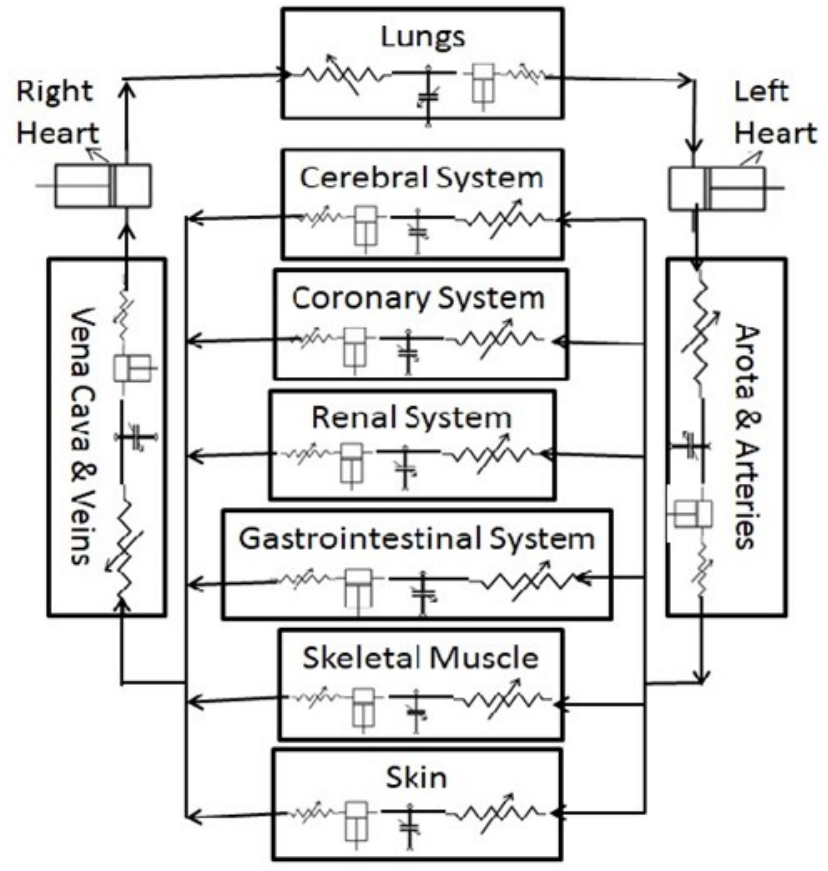

Fig 1: Blood Flow through Different Systems

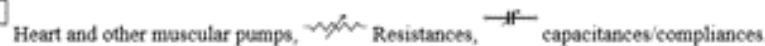




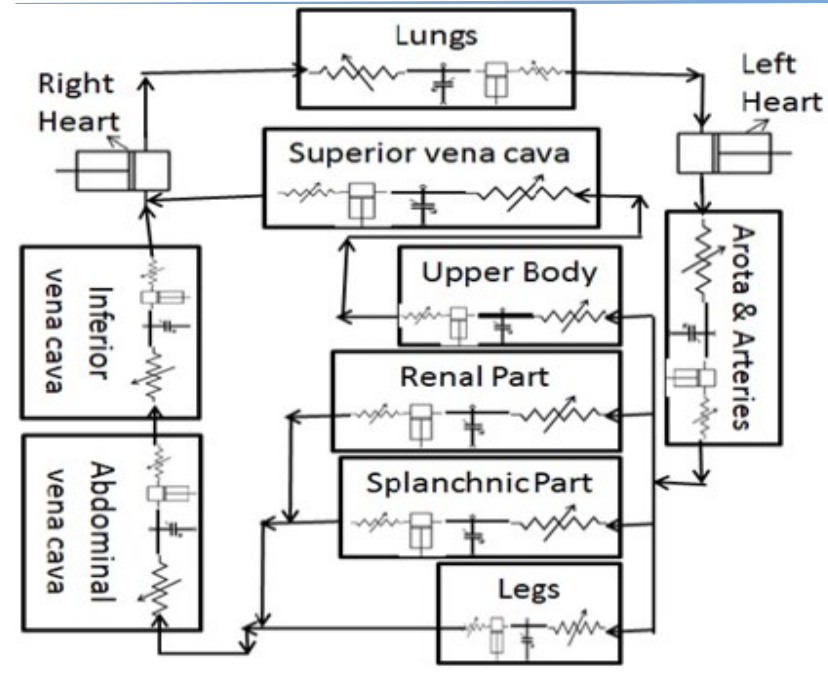

Fig 2. Blood Flow through Body Parts

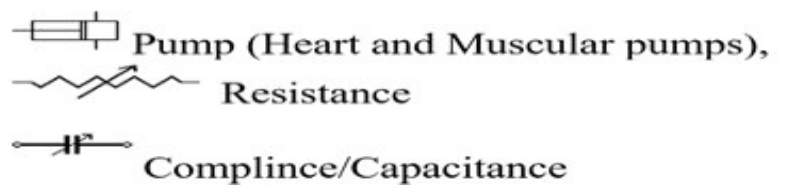

The resistance of a circuit consisting of series of resistances is the sum of individual resistances, whereas in case of parallel resistances; the inverse of system resistance is the sum of inverse of individual resistances. The compliance of a system $(\mathrm{C}$ in $\mathrm{ml} / \mathrm{mm} \mathrm{Hg})$ is the ratio of change in volume of the system (DV) and change in Pressure of the system (DP) or ratio of volume (V) and pressure $(\mathrm{P})(\mathrm{C}=\mathrm{DV} / \mathrm{DP})$ or $\mathrm{V} / \mathrm{P})[1]$.

The Resistance offered by Capacior (X) having capacitance (C) operating in electrical circuit with frequency (f) is given by: $X=1 /\left(2 \pi * f^{*} \mathrm{C}\right)$ [24]. Accordingly the Resistance ( $\mathrm{X}$ in $\mathrm{mm} \mathrm{Hg} / \mathrm{ml}$ ) offered by Compliance in circulatory system is given by: $\mathrm{X}=1 /$ $(2 \pi * n * C)$ where $n$ is heart rate. The total resistance of a circuit $(Z)$ consisting of Resistance $R$ and Resistance $X$ due to capacitance $C$ is given by: $Z=$ square $\operatorname{root}\left(R^{\wedge} 2+\right.$ $\left.\mathrm{X}^{\wedge} 2\right)$ [24]. Accordingly total resistance $(\mathrm{Z}$ in $\mathrm{mm} \mathrm{Hg} / \mathrm{ml})$ of the part with Resistance offered by Resistances ( $\mathrm{R}$ in $\mathrm{mm} \mathrm{Hg} / \mathrm{ml}$ ) and Resistance offered by Compliance (X) in circulatory system is given by: $Z=$ square root $\left(\mathrm{R}^{\wedge} 2+\right.$ $\left.\mathrm{X}^{\wedge} 2\right)$. Voltage Drop (V) in portion of electrical circuit is given by Ohms law: $\mathrm{V}=$ Current through the Circuit (I) * Resistance of the portion of electrical circuit (R) [24]. Similarly Pressure Drop (DP in $\mathrm{mm} \mathrm{Hg}$ ) across a part of circulatory system with total resistance $(Z)$ and blood flow through it $(\mathrm{Q}$ in $\mathrm{ml} / \mathrm{sec})$ is given by: $\mathrm{DP}=\mathrm{Z}^{*} \mathrm{Q}$. The Pressure at the outlet of a subsystem in circulatory system is given by: $(\mathrm{Po})=$ Pressure at the inlet of the system $(\mathrm{Pi})$ - Pressure drop by total resistance + Pressure developed by muscular pump in the system.

Resistances and Compliances of a few parts of the circulatory system are available in the paper published by Kim et al [21]. Volume of Blood stored in different parts of circulatory system and pressure at different points of circulatory systems are collected from Literature [1]. Total blood flow and blood flow through different body parts were calculated from data available in literatue [1], $[2,25]$. From the collected and calculated data and applying Kirchoffs voltage law and Kirchoffs current law in fluid flow system, drawing analogy to electrical system, and the relationship between different parameters, the value of different parameters has been computed according to models in Figure 1 and in Figure 2 and are given in Table 1 and Table 2 respectively.

\section{Mathematical Models:}

The Stroke Volume (SV) is a function of venous return $(\mathrm{Vr})$ and the Heart Rate (n) depends on non-modifiable factors \{age (Ag), gender (Ge) and ethinicity (Et) $\}$ and modifiable factors \{Physiological and Pathological factors (Pf), Lifestyle factors (Lf), Neuropsychological factors (Nf), and Environmental factors (Ef). The blood flow discharged by heart (Q) is a function of all these factors.

$\mathrm{Q}(\mathrm{Vr}, \mathrm{Ag}, \mathrm{Ge}, \mathrm{Et}, \mathrm{Pf}, \mathrm{Lf}, \mathrm{Nf}, \mathrm{Ef})=\mathrm{SV}(\mathrm{Vr}) * \mathrm{n}(\mathrm{Ag}, \mathrm{Ge}$, Et, Pf, Lf, Nf, Ef)

Mean Blood Pressure (BMP) developed by Heart depends on $\mathrm{Q}$ and Resistance of the system (R). R depends on viscosity of blood (h), effective length (l) and effective radius (r) of blood vessel. Viscosity of blood depends on composition and hence can be written as function of blood composition also.

BMP(Vr, Ag, Ge, Et, Pf, Lf, Nf, Ef, h, r, l) = Q(Vr, Ag, Ge, Et, Pf, Lf, Nf, Ef) * R(h, r, l) -pressure developed by muscular pump (Mp).

Blood Pressure (BP) is the sum of BMP and Pulse Pressure (PP).

$\mathrm{PP}(\mathrm{n}, \mathrm{t})=\mathrm{A} * \mathrm{n}^{\wedge} 2 * \operatorname{Cos}(2 \pi * \mathrm{n} * \mathrm{t}+\pi)$ (3), time $(\mathrm{t})=0$ means diastolic pressure.

$\mathrm{BP}(\mathrm{Vr}, \mathrm{Ag}, \mathrm{Ge}, \mathrm{Et}, \mathrm{Pf}, \mathrm{Lf}, \mathrm{Nf}, \mathrm{Ef}, \mathrm{h}, \mathrm{r}, \mathrm{l}, \mathrm{t})=\mathrm{BMP}(\mathrm{Vr}, \mathrm{Ag}$, Ge, Et, Pf, Lf, Nf, Ef, h, r, l) $+A * n^{\wedge} 2 * \operatorname{Cos}\left(2 \pi * n^{*} t+\right.$ $\pi) \ldots \ldots \ldots \ldots \ldots \ldots(4)$

When the value of Cos $\left(2 \pi^{*} n^{*} t+\pi\right)$ is +1 , the Blood Pressure is systolic pressure and when the value of Cos $\left(2 \pi^{*} n * t+\pi\right)$ is $(-) 1$, the Blood Pressure is diastolic pressure.

Blood Pressure at Periphery $(\mathrm{BPp})=\mathrm{BP}-$ Resistance from heart to Peripheral Part $(\mathrm{Rp}) *$ Blood Flow through that peripheral Part (Qp) + Pressure developed by muscular pump (Mp).

Data Collection: Primary data was collected from people of different part of India by stratified random sampling basis. The data was taken randomly from the persons came in different health centres for health check-up. The values of blood pressures, heart rates at different levels of work, provided by health centres to them were taken as primary data. The data was taken only from them who were willing to provide the same knowing the purpose of the data collection. The age group of the persons was 1840 years. All of the persons were free from any disease.

Secondary Data Analysis: Cardiac output is $5300 \mathrm{ml} /$ minute when a person is at rest and linearly it increases with exercise [2]. From the data the equation of cardiac output ( $\mathrm{Q}$ in $\mathrm{ml} / \mathrm{minute}$ ) that is discharge of heart for different level of exercise ( $\mathrm{W}$ in watt) is derived as follows: $\mathrm{Q}=5300+96.36 * \mathrm{~W} \mathrm{ml} /$ minute or

$\mathrm{Q}=88.333+1.606 * \mathrm{~W} \mathrm{ml} /$

second..... 


\section{Results}

Analysis of Primary data indicates correlation exists between exercise level and heart rate as follows:

$\mathrm{n}=(72+0.52 * \mathrm{~W})$. ..(7), heart rate in beats per minute and work $(\mathrm{W})$ in watt.

The peripheral system can change the resistance to fulfil its blood flow requirement. So the pressure drop across the system remains constant and from the Table 1 , it is found to be $70 \mathrm{~mm}$ of $\mathrm{Hg}$. The pressure dropped in entire system is $100 \mathrm{~mm} \mathrm{Hg}$.

Pressure developed by heart at starting of arota is given by:

$\mathrm{BP}$ heart $=70+\mathrm{Q} *$ (Resistance of Arota + Resistance of Arteries + Resistance of Veins + Resistance of Vena Cava) - Pressure developed by Muscular pumps + A * $\mathrm{n}^{\wedge} 2 * \operatorname{Cos}\left(2 \pi^{*} \mathrm{n} * \mathrm{t}+\pi\right)$. Substituting values of cardiovascular parameters from Table 1 , value of $\mathrm{Q}$ in equation (6), relationship between parameters obtained from primary data analysis and computed value of $A$, we have:

BP heart $=71.0+0.402597 * n+\left(0.00008 * n^{\wedge} 2+\right.$ $0.34 * n-5) * \operatorname{Cos}(2 \pi * n * t+\pi) \ldots . .(8)$

Substituting the value of heart rate (n) from equation (7) to equation (8) we have

BP heart $=100+0.209 * \mathrm{~W}+(20+0.185 * \mathrm{~W}+$ $\left.0.000022 * W^{\wedge} 2\right) * \operatorname{Cos}\{2 \pi *(1.2+0.00867 * W) * t+\pi)$ (9), at rest $\mathrm{W}=0$.

Substituting value of Cosine function with $(-) 1$ and +1 , in equation (9) we have:

Diastolic Pressure $=100+0.209 * \mathrm{~W}-(20+0.185 * \mathrm{~W}+$ $\left.0.000022 * \mathrm{~W}^{\wedge} 2\right)$

Systolic Pressure $=100+0.209 * \mathrm{~W}+\left(20+0.185^{*} \mathrm{~W}+\right.$ $0.000022 * \mathrm{~W}^{\wedge} 2$ )

Pressure at arota and large arteries is same as BPheart. At small arteries pressure is given by:

$\mathrm{BPsa}=90+0.1306 * \mathrm{~W}+(12.5+0.1156 * \mathrm{~W}+$ $\left.0.00001375 * \mathrm{~W}^{\wedge} 2\right) * \operatorname{Cos}(2 \pi *(1.2+0.00867 * \mathrm{~W}) * \mathrm{t}+\pi)$ (10)

Pressure at any part of cardiovascular system can be obtained from equation (5) as derived in developing mathematical models. For capillaries and veins coefficient of Cos function is zero as large capacitance associated with this part absorbs time varying component.

The systolic and diastolic blood pressure as calculated from equation (9) with value of Cosine function as +1 and (-) 1 respectively, for rest and different level of exercise is shown in Figure 3. Similarly the blood pressure at rest and different level of exercise as a function of time as obtained from equation (9) is shown in Figure 4.

The average error of model as calculated in terms of percentage deviation of predicted value of model from primary data are $0.91 \%, 0.99 \%$ and $0.49 \%$ for heart rate, systolic blood pressure and diastolic pressure respectively. The modulus of individual error that is converting negative error to positive is taken for finding an average error. The error was taken for the level of exercise for which primary data could be collected. The primary data is also validated from t-test with $\mathrm{p}$ value less than 0.01 .

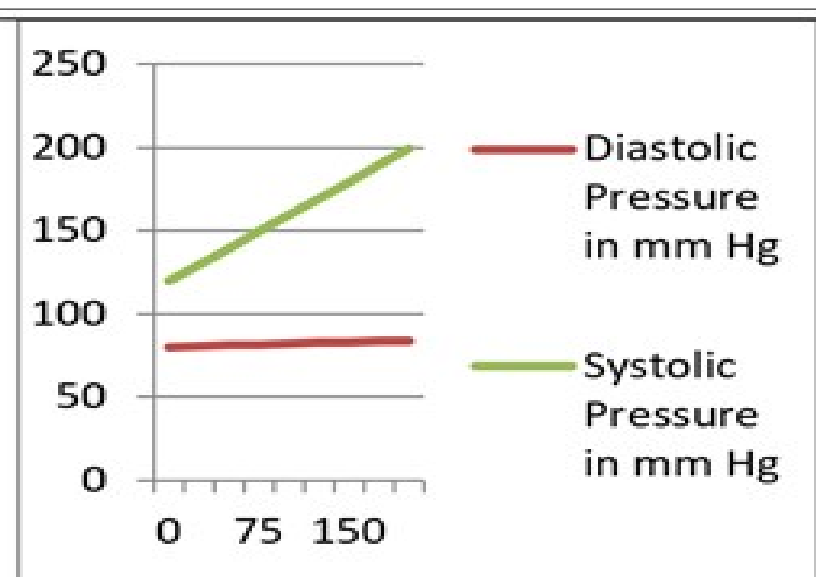

Level of Exercise in Watt $\rightarrow$

Fig 3: Variation of Systolic and Diastolic Pressure with exercise

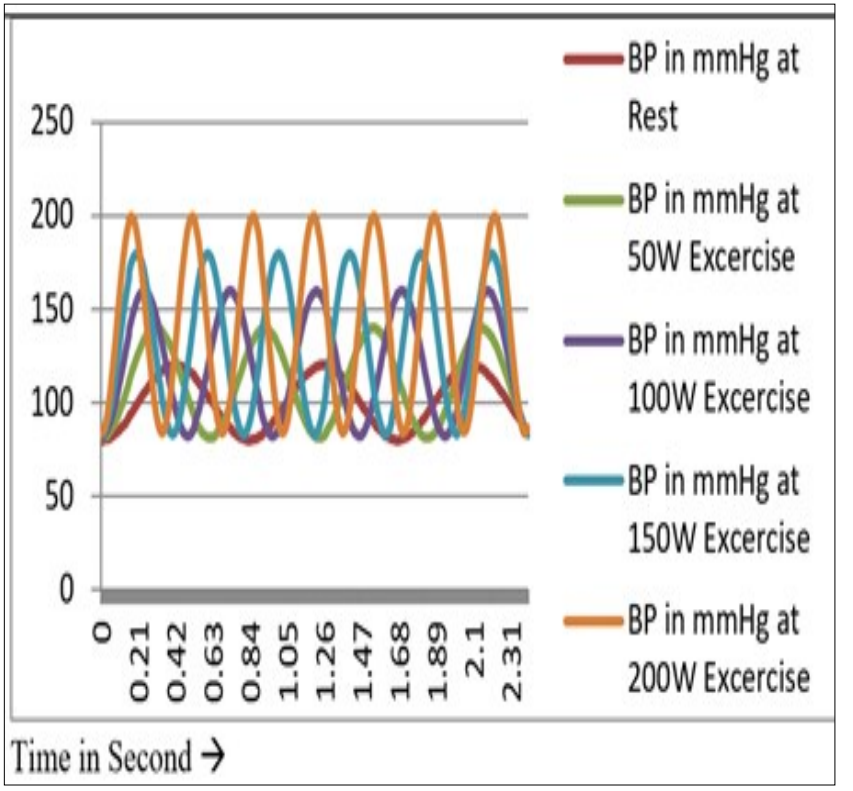

Fig 4: Variation of Blood Pressure (BP) at different level of Exercise with time

Validation of Model:

\begin{tabular}{|c|c|c|c|c|c|c|}
\hline \multirow{2}{*}{$\begin{array}{l}\text { Level } \\
\text { of } \\
\text { Exer- } \\
\text { cise }\end{array}$} & \multicolumn{3}{|c|}{$\begin{array}{l}\text { Calculated from Equation } \\
(9)\end{array}$} & \multicolumn{3}{|c|}{ Primary Data } \\
\hline & $\mathrm{HR}$ & SBP & $\begin{array}{l}\text { Dias- } \\
\text { tolic } \\
\text { BP }\end{array}$ & $\begin{array}{l}\text { Hear } \\
\text { Rate } \\
\text { beats/min }\end{array}$ & $\begin{array}{l}\text { Systolic } \\
\text { BP } \\
\mathrm{mmHg}\end{array}$ & $\begin{array}{l}\text { Diastolic } \\
\mathrm{BP} \\
\mathrm{mmHg}\end{array}$ \\
\hline Watt & $\begin{array}{l}\text { beats/ } \\
\text { min }\end{array}$ & $\begin{array}{l}\mathrm{mmH} \\
\mathrm{g}\end{array}$ & $\begin{array}{l}\mathrm{mmH} \\
\mathrm{g}\end{array}$ & $\begin{array}{l}\text { Mean } \pm \\
\text { SD }\end{array}$ & $\begin{array}{l}\text { Mean } \pm \\
\text { SD }\end{array}$ & $\begin{array}{l}\text { Mean } \pm \\
\text { SD }\end{array}$ \\
\hline 0 & 72 & 120 & 80 & $72 \pm 7$ & $120 \pm 7$ & $80 \pm 6$ \\
\hline 25 & 85 & 129.9 & 80.6 & $84 \pm 9$ & $126 \pm 8$ & $80.2 \pm 6$ \\
\hline 50 & 98 & 139.8 & 81.1 & $96 \pm 8$ & $138 \pm 9$ & $80.6 \pm 7$ \\
\hline 75 & 111 & 149.7 & 81.7 & $110 \pm 10$ & $148 \pm 10$ & $81.1 \pm 8$ \\
\hline 100 & 124 & 159.6 & 82.2 & $123 \pm 9$ & $159 \pm 12$ & $82 \pm 10$ \\
\hline 125 & 137 & 169.6 & 82.7 & $138 \pm 11$ & $170 \pm 12$ & $82 \pm 10$ \\
\hline 150 & 150 & 179.6 & 83.1 & $151 \pm 13$ & $181 \pm 14$ & $83 \pm 12$ \\
\hline 175 & 163 & 189.6 & 83.5 & \multirow{2}{*}{\multicolumn{3}{|c|}{ Data could not be collected }} \\
\hline 200 & 176 & 199.7 & 83.9 & & & \\
\hline
\end{tabular}

Int. J. Curr. Res. Physiol. Pharmacol. 2020;4(2):4-10 
Table 1. Cardiovascular parameters as per model in figure 1

\begin{tabular}{|l|r|r|r|r|r|r|r|r|}
\hline \multirow{2}{*}{ Circulatory System } & $\begin{array}{l}\text { Inlet } \\
\text { Resistance }\end{array}$ & $\begin{array}{l}\text { Outlet } \\
\text { Resistance }\end{array}$ & Compliance & $\begin{array}{l}\text { Resistance of } \\
\text { Compliance }\end{array}$ & $\begin{array}{l}\text { Total } \\
\text { Resistance }\end{array}$ & Flow & $\begin{array}{l}\text { Pressure } \\
\text { drop }\end{array}$ & $\begin{array}{l}\text { Pressure } \\
\text { Developed } \\
\text { by pump }\end{array}$ \\
\cline { 2 - 10 } & $\mathrm{mm} \mathrm{Hg} / \mathrm{ml}$ & $\mathrm{mm} \mathrm{Hg} / \mathrm{ml}$ & $\mathrm{ml} / \mathrm{mm} \mathrm{Hg}$ & $\mathrm{mm} \mathrm{Hg} / \mathrm{ml}$ & $\mathrm{mm} \mathrm{Hg} / \mathrm{ml}$ & $\mathrm{ml} / \mathrm{min}$ & $\mathrm{mm} \mathrm{Hg}$ & $\mathrm{mm} \mathrm{Hg}$ \\
\hline Lungs & 0.1 & 0.04 & 0.1 & 0.02 & 0.142 & 5300 & 13 & 3 \\
\hline Cerebral System & 6.56 & 0.48 & 0.010 & 0.22 & 7.043 & 710 & 83 & 13 \\
\hline Coronary System & 19.68 & 1.44 & 0.003 & 0.66 & 21.130 & 233 & 82 & 12 \\
\hline Renal System & 4.1 & 0.3 & 0.016 & 0.14 & 4.402 & 1135 & 83 & 13 \\
\hline Gastrointestinal & 3.2 & 0.21 & 0.020 & 0.11 & 3.412 & 1420 & 81 & 11 \\
\hline System & 3.35 & 0.27 & 0.020 & 0.11 & 3.622 & 1420 & 86 & 16 \\
\hline Skeletal Muscle & 12.5 & 0.9 & 0.005 & 0.41 & 13.406 & 382 & 85 & 15 \\
\hline Skin & 0.08 & 0.02 & 0.03 & 0.07 & 0.124 & 5300 & 11 & 1 \\
\hline Arota \& arteries & 0.2 & 0.08 & 0.39 & 0.01 & 0.280 & 5300 & 25 & 6 \\
\hline Vena Cava \& veins & & & & & & & &
\end{tabular}

Table 2: Cardiovascular parameters as per model in figure 2

\begin{tabular}{|l|r|r|r|r|r|r|r|r|}
\hline \multirow{2}{*}{ Circulatory System } & $\begin{array}{l}\text { Inlet } \\
\text { Resistance }\end{array}$ & $\begin{array}{l}\text { Outlet } \\
\text { Resistance }\end{array}$ & Compliance & $\begin{array}{l}\text { Resistance of } \\
\text { Compliance }\end{array}$ & $\begin{array}{l}\text { Total } \\
\text { Resistance }\end{array}$ & Flow & $\begin{array}{l}\text { Pressure } \\
\text { drop }\end{array}$ & $\begin{array}{l}\text { Pressure } \\
\text { Developed } \\
\text { by pump }\end{array}$ \\
\cline { 2 - 10 } & $\mathrm{mm} \mathrm{Hg} / \mathrm{ml}$ & $\mathrm{mm} \mathrm{Hg} / \mathrm{ml}$ & $\mathrm{ml} / \mathrm{mm} \mathrm{Hg}$ & $\mathrm{mm} \mathrm{Hg} / \mathrm{ml}$ & $\mathrm{mm} \mathrm{Hg} / \mathrm{ml}$ & $\mathrm{ml} / \mathrm{min}$ & $\mathrm{mm} \mathrm{Hg}$ & $\mathrm{mm} \mathrm{Hg}$ \\
\hline Lungs & 0.1 & 0.04 & 0.1 & 0.02 & 0.142 & 5300 & 13 & 3 \\
\hline Cerebral System & 6.56 & 0.48 & 0.010 & 0.22 & 7.043 & 710 & 83 & 13 \\
\hline Coronary System & 19.68 & 1.44 & 0.003 & 0.66 & 21.130 & 233 & 82 & 12 \\
\hline Renal System & 4.1 & 0.3 & 0.016 & 0.14 & 4.402 & 1135 & 83 & 13 \\
\hline Gastrointestinal & 3.2 & 0.21 & 0.020 & 0.11 & 3.412 & 1420 & 81 & 11 \\
\hline System & 3.35 & 0.27 & 0.020 & 0.11 & 3.622 & 1420 & 86 & 16 \\
\hline Skeletal Muscle & 12.5 & 0.9 & 0.005 & 0.41 & 13.406 & 382 & 85 & 15 \\
\hline Skin & 0.08 & 0.02 & 0.03 & 0.07 & 0.124 & 5300 & 11 & 1 \\
\hline Arota \& arteries & 0.2 & 0.08 & 0.39 & 0.01 & 0.280 & 5300 & 25 & 6 \\
\hline Vena Cava \& veins & & & & & & & &
\end{tabular}

\section{Research Findings:}

$\Rightarrow$ Blood Pressure at any Part of human body depends on heart rate $(n)$ and is given by $\mathrm{BP}=\mathrm{A}+\mathrm{B}^{*} \mathrm{n}+\left(\mathrm{C}^{*} \mathrm{n}^{\wedge} 2\right.$ $\left.+D^{*} n+E\right) * \operatorname{Cos}(2 \pi * n * t+\pi)$, where A, B, C, D and $\mathrm{E}$ constant for a particular point in the cardiac system, time (t) is measured from diastolic pressure. The value of cosine function is -1 for diastolic pressure and +1 for systolic pressure.

$\Rightarrow \mathrm{BP}=\mathrm{P}+\mathrm{Q} * \mathrm{~W}+\left(\mathrm{R}^{*} \mathrm{~W}^{\wedge} 2+\mathrm{S} * \mathrm{~W}+\mathrm{T}\right)^{*} \operatorname{Cos}\left(2 \pi^{*}\right.$ $(1.2+0.00867 * \mathrm{~W}) * \mathrm{t}+\pi)$, where $\mathrm{P}, \mathrm{Q}, \mathrm{R}, \mathrm{S}$ and $\mathrm{T}$ constant for a particular point in the cardiac system and $\mathrm{W}$ is the work level of the person which is zero at rest and negative if the energy requirement of the body goes down below the level of normal energy requirement of the body, time $(\mathrm{t})$ is measured from diastolic pressure. The value of cosine function is -1 for diastolic pressure and +1 for systolic pressure.

$\Rightarrow$ Value of Pulse Pressure (cosine part) is negligible in vena cava, veins, venules and capillaries as high capacitance/compliance (C) associated with them absorb the pulsating component similar to electrical capacitors.

$\Rightarrow$ The pressures produced by muscles (muscular pumps), resistances and compliances of different parts in circulatory system were computed and were shown in Table 1 and 2.

$\Rightarrow$ Heart Rate increases linearly with energy requirement of body

\section{Discussion}

Research findings indicates that laws of physics holds good for circulatory system. The heart is like a variable speed variable stroke length reciprocatory pump. The pressure developed by pump can be calculated as a function of time and systolic and diastolic pressure can be obtained. When body needs more energy more blood is required and this is achieved by increasing heart rate like speed of a pump. The constant terms of the blood pressure equations

Are constant for a normal healthy person. The deviation of this constants for a person during rest or exercise indicates some problem in either blood constituent or circulatory system or in the control system governing heart rate and stroke length.

Equation (2) relates blood pressure with blood flow and system resistance each of which is function of different cardiovascular system parameters. Hence the reason for changing normal blood pressure can be attributed to those 
parameters and further investigation about those parameters shall help to identify the exact reason of the problem.

Application of Model: The model can be used to know the variation of blood pressure with time for rest as well as any level of exercise. It can be used to predict blood pressure at any component in the circulatory system.

From the model Resistance in any part of the system is known and by measuring pressure drop of any person actual Resistance can be calculated. If the resistance is more it indicates radius of the blood vessel has reduced (Resistance is inversely proportional to the $4^{\text {th }}$ power of radius). So by measuring blood pressure, the blockage of blood vessel can be identified.

Establishing relation between resistance of blood vessels with composition of blood (Sodium, Potassium etc), the blood composition can be changed to normal level.

The comparison of systolic and diastolic pressure variation of a person with the modelled data shall predict if person is suffering any cardiovascular disease.

\section{Conclusion}

The cardiovascular system can be modelled as equivalent electrical system or fluid flow system. Relation can be established among different cardiovascular parameters and the cardiovascular system can be modelled mathematically which shall provide necessary information with more than $99 \%$ accuracy. The system changes the parameters like resistances, compliances, heart rate as per the requirements. The energy requirement of the body has strong relationship with cardiovascular system parameters and the same can be predicted with more than $99 \%$ accuracy.

Direction for future research: Effect of all variables on different cardiovascular parameters as developed in developing mathematical model section needs further research. This will open a lot of windows in clinical research.

\section{Source of funding: Self}

\section{Conflict of Interest: Nil}

\section{References}

[1] Constanzo LS. Cardiovascular Physiology, Physiology, Elsevier, 6th Edition, page 117- 86.

[2] Guyton AC, Hall JE. The Heart, Textbook of Medical Physiology, Elsevier, 12th edition, page 101 $-281$

[3] Agyei B, Nicolaou M, Boateng L, Dijkshoorn H, Born BJV D, Agyemang C. Relationship between psychosocial stress and hypertension among Ghanaians in Amsterdam, the Netherlands - the GHAIA study, BMC Public Health. 2014; 14:Article number: 692

[4] Hu B, Liu X, Yin X, Fan H, Feng F, Yuan J. Effects of Psychological Stress on Hypertension in MiddleAged Chinese: A Cross-Sectional Study. 2015;4:PLOS ONE.
[5] Huai P, Xun H, Reilly K, Wang Y, Ma W, Xi B, Physical Activity and Risk of Hypertension-A MetaAnalysis of Prospective Cohort Studies, Hypertension. 2013;62:1021-6

[6] Lelong H, Galan P, Guyot EK, Fezeu L, Hercberg S, Blacher J. Relationship Between Nutrition and Blood Pressure: A Cross-Sectional Analysis from the NutriNet-Santé Study, a French Web-based Cohort Study. American Journal of Hypertension.2015;28 (3): $362-71$

[7] Shah E, Smith GD, Lowering blood pressure: a systematic review of sustained effects of nonpharmacological interventions. Journal of Public Health Medicine. 1998,;29(4):441-8

[8] Taft C, Hallberg I, Bengtsson U, Manhem K, Kjellgren K. Links between blood pressure and medication intake, well-being, stress, physical activity and symptoms reported via a mobile phonebased self-management support system: a cohort study in primary care, BMJ Open. 2018; 8:e020849.

[9] Trapp M, Trapp EM, Egger JW, Domej W, Schillaci G, Avian A. Impact of Mental and Physical Stress on Blood Pressure and Pulse Pressure under Normobaric versus Hypoxic Conditions. Plos One. 2014;9(5):e89005

[10] Matthews CE, Chen KY, Freedson PS, Buchowski MS, Beech BM, Pate RR, Troiano RP. Amount of Time Spent in Sedentary Behaviors in the United States, 2003-2004, American Journal of Epidemiology, 2008;167(7):875-81

[11] Dickey RA, Janick JJ. Lifestyle modifications in the prevention and treatment of hypertension, Endocrine Practice, 2001;7(5):392-9

[12] Fatisson J, Oswald V, Lalonde F. Influence diagram of physiological and environmental factors affecting heart rate variability: an extended literature overview, Heart Int. 2016;11(1): e32-e40

[13] Kotchen JM, Mckean HE, Kotchen TA. Blood Pressure Trends With Aging, Hypertension, 1982; 4 (5 Pt 2):III: 128-34

[14] Bowman TS, Howard TS, Gaziano JM. Effect of Age on Blood Pressure Parameters and Risk of Cardiovascular Death in Men, American Journal of Hypertension, 2006; 19:47-52

[15] Rockwood M. R. H., Howlett S. E., Blood Pressure in Relation to Age and Frailty, Canadian Geriatrics Journal, 2011;14(1):2-7.

[16] Penuela R, Penuela T. Relationship between blood pressure, age, gender, body mass index and short Term blood pressure variability in untreated hypertensive patients, Journal of Hypertension. 2015;33:e286.

[17] Lelong H, Galan P, Guyot EK, Fezeu L, Hercberg S, Blacher J. Relationship Between Nutrition and Blood Pressure: A Cross-Sectional Analysis from the NutriNet-Santé Study, a French Web-based Cohort Study. American Journal of Hypertension.2015;8(3): 362-71. 
[18] Ehret BG. Genetics of Hypertension, Hypertension: A Companion to Braunwald's Heart Disease, Elsevier, $3^{\text {rd }}$ Edition. 15-25

[19] Price RS, Kasner SE. Neurologic Aspects of Systemic Disease, Handbook of Clinical Neurology, Elsevier, 1st Edition.2014;119: 10-750. Part 1

[20] Touyz RM. Blood Pressure Regulation and Pathology, Cellular and Molecular Pathobiology of Cardiovascular Disease, Academic Press, 1st edition, page $257-75$.

[21] Kim YT, Lee JS, Youn CH, Choi JS, Shim EB. An Integrative Model of the Cardiovascular System Coupling Heart Cellular Mechanics with Arterial Network Hemodynamics, Journal of Korean Medical
Science, 2013, published at https:// www.ncbi.nlm.nih.gov/pmc/articles/PMC3744703/.

[22] Boyd JHW, Westfall R, Stasch SF. Sample Size, Marketing Research, Text and Cases, Richard D Irwin, Inc., Honewood, Illinois, seventh edition, p. 60430.

[23] Bansal RK. Reciprocating Pumps, A Textbook of Fluid Mechanics and Hydraulic Machines, Laxmi Publications (P) Ltd. Revised 9th Edition, 993-1040

[24] Chattopadhyay D, Rakshit PC. Basic Circuit elements, Fundamentals of Electric Circuit Theory, S. Chand $7^{\text {th }}$ Revised Edition, page 10-100

[25] Guyton AC, Hall JE. The Heart, Textbook of Medical Physiology, Elsevier ,13th International edition, page 107-302. 